\title{
Simplifying the care plan documentation procedure - An interview study with nurses at a medical ward at a university hospital in Sweden
}

\author{
Helena Larsson ${ }^{1}$, Danijela Handanovic ${ }^{1}$, Kristina Rosengren*1,2 \\ ${ }^{1}$ Sahlgrenska Academy, Institute of Health and Care Sciences, University of Gothenburg, Sweden \\ ${ }^{2}$ Region Västra Götaland, Sahlgrenska University Hospital, Department of Internal Medicine, Gothenburg, Sweden
}

Received: June 11, 2019

DOI: $10.5430 /$ jha.v8n4p54

\author{
Accepted: July 11, 2019 \\ Online Published: July 30, 2019
}

\begin{abstract}
Objective: Swedish healthcare is experiencing an ongoing change from a biomedical perspective to person-centered care (PCC). Therefore, a transition in documentation of assessment, care and treatment is needed. The aim of this study was to describe nurses' experiences with care plans at a university hospital medical ward in Western Sweden.

Methods: Six semistructured interviews were conducted with nurses, and the data were analyzed using a qualitative content analysis with an inductive approach.

Results: Nurses' experiences with working with care plans were described as improving patient safety and included the following three subcategories: managing a high workload, collaboration improves documentation and creating structure in the medical records. In summary, nurses highlight a lack of time and team collaboration as important denominators in creating conditions for mutual care plans.

Conclusions: Working with care plans is an important part of a nurse's work. Procedure, use of documentation and ensuring regular revision all influence the quality of care due to the simple and clear structure of documentation within the medical record. To strengthen the patient's involvement in a mutual care plan, nurses play a key role in implementing PCC, which is a tool used to improve partnerships between patients and health professionals.
\end{abstract}

Key Words: Care plan, Medical records, Nursing, Patient-centred care, Qualitative content analysis

\section{INTRODUCTION}

Researches ${ }^{[1-4]}$ have shown that patients who participate in their care plans create better conditions for health and wellbeing. Therefore, person-centered care (PCC) is stressed as one possibility to focus the patient narrative as the basis for implementing a care plan in the medical record. Implementing PCC includes a partnership between patients and staff, which is the starting point of a shared narrative that is discussed and agreed upon, resulting in a mutual care plan. The present study will focus on care plan documentation within medical records to broaden knowledge regarding patient safety.

\section{BACKGROUND}

Historically, healthcare has been based on a biomedical approach in which illness is usually described as something that

\footnotetext{
${ }^{*}$ Correspondence: Kristina Rosengren; Email: kristina.rosengren@gu.se; Address: Sahlgrenska Academy, Institute of Health and Care Sciences, University of Gothenburg, SE-405 30 Gothenburg, Sweden.
} 
affects humans and is managed by health professionals; therefore, participation of the patient perspective is rare. ${ }^{[5]}$ Nursing work changed from supporting physicians to promoting health by preventing illness, alleviating suffering, and promoting equality for people's rights and self-determination. ${ }^{[6]}$ A nurse's competence includes scientific knowledge as well as a humanistic view of humanity; the six core competencies are PCC, patient safety, informatics, teamwork, evidencebased care and quality improvement. However, Jansson and Forsberg ${ }^{[7]}$ highlighted the need to change nurses' attitudes towards scientific research and to absorb and use research, such as PCC.

Nurses are well equipped for nursing and are capable of planning and communicating with patients, their relatives and team members. A nurse's main task is to coordinate nursing with a broadened knowledge based on the perspectives of the health professionals and patients documented within a care plan. ${ }^{[8]}$ The patient act in Sweden ${ }^{[9]}$ emphasizes a patient's right to participate in healthcare based on individual circumstances. According to the philosopher Paul Ricoeur, ${ }^{[10]}$ every human being strives for "the good life". People respond to and judge their own actions in the context of ethical values and are vulnerable to suffering during life. A person is part of society through relationships with others, but conflicts arise towards one's own self-perceptions and interpretations by others regarding what is right and wrong due to different moral views. Solutions to life are reached by visualizing different perspectives for equal relationships and understanding that persons are able to speak and act. ${ }^{[10]}$ The Center for Person-Centered Care at the University of Gothenburg, GPCC, ${ }^{[1]}$ supports and carries out high quality research. PCC can be described with three key concepts: partnership (mutual respect for the staff's, patient's, and relatives' knowledge and expertise), narrative/story (listening to the patient regarding their condition combined with examinations) and documentation (care plan and medical record). Partnership is the foundation of PCC, which relies on mutual trust between patients and health professionals. Therefore, the GPCC ${ }^{[11]}$ has developed and tested care plans that are printed out (on paper) for patients during their hospital stay and admission.

Nursing should be designed and implemented in consultation with the patient using structures such as VIPS (Well-being, Integrity, Prevention and Safety), a Swedish documentation care model to identify and collect needs based on the nursing process. $^{[8,12,13]}$ Other common documentation models are NANDA-I, North American Nursing Diagnosis-International and ICNP, International Classification for Nursing Practice, which are used to classify nursing. ${ }^{[14,15]}$ A care plan is one part of the medical record and traditionally is a tool for health professionals that includes the background of care, assess- ments and decisions made in connection with the hospital stay. ${ }^{[15]}$ Research $^{[16]}$ has shown that nurses use approximately $50 \%$ of their work time to document nursing activities; thus, a paradigm shift is needed to improve time with patients, such as using the bedside shift report to improve patient safety and nurse accountability with less administration. ${ }^{[17]}$ Moreover, changes are needed to achieve patientsafe documentation, such as checklists/templates, as competent and well-trained staff members who act in accordance with established structures, terms and concepts for medical record documentation. ${ }^{[12,13]}$ One perspective is continuity in documentation within medical records, which requires clear consent information for healthcare activities, such as treatment. ${ }^{[18]}$ Challenges due to adaptation and reuse of data that minimizes duplication of data are stressed, therefore, medical record documentation requires good communication between patients and health professionals as well as a supportive IT system. ${ }^{[19]}$ To ensure the performance of high quality care, nurses collaborate in teams to retrieve information from different perspectives (the patient's story and expert knowledge from different health professionals). Teamwork is counteracted by various professional barriers as healthcare structure, including a lack of communication platforms, staff shortages, and a high workload. ${ }^{[20,21]}$

The medical record system is limited, which is a challenge for the ability of health professionals to document information in a person-centered manner (i.e., visualization of an overall picture of the patient's state of health) as opposed to providing information solely from a biomedical perspective. ${ }^{[1,22,23]}$ Kitwood and Bredin ${ }^{[24]}$ introduced PCC in dementia care in the UK in the early 1990s. This paradigm shift in dementia care addressed patients who previously were regarded as living dead, with only their basic physical needs prioritized. For example, Chevakasemsook et al. ${ }^{[25]}$ highlights that restrictions within medical records cause problems due to documentation of care plans with a humanistic perspective. Moreover, research ${ }^{[1,2,26]}$ has shown that listening to patients facilitates joint agreement, which shortens the hospital stay and reduces costs by maintain continuity and partnership across professional boundaries. However, mutual care plans are described as tool of professional caregivers, not the patients. ${ }^{[26]}$ Therefore, PCC plans appear to require knowledge concerning how to document a patient's feelings, commitment and preferences, which are crucial factors for PCC plan implementation. ${ }^{[23]}$ For example, Horrel et al. ${ }^{[27]}$ developed and tested coordinated PCC (P3C) in United Kingdom by developing routines for active listening, shared decision-making and coordinated work regarding care plan documentation. Accordingly, nursing documentation is stressed as a time-consuming and challenging task. There- 
fore, the aim of the study was to describe nurses' experiences with care plans at a university hospital internal medical ward in the western part of Sweden.

\section{MethodS}

\subsection{Settings}

Sahlgrenska University Hospital ${ }^{[28]}$ is one of the largest workplaces in the county council of Västra Götaland, Sweden, with approximately 16,000 employees who are divided into 120 departments and located at four different hospitals in the Gothenburg area, namely, Sahlgrenska Hospital, Eastern Hospital, Mölndal Hospital and Högsbo Hospital. The medical department where the study was conducted includes four wards and one outdoor clinic.

\subsection{Design}

This study used content analysis, a qualitative method that involves an inductive approach, to increase the understanding of nurses' voices, views and thoughts about their work due to care plans. This method reveals conflicting opinions and unresolved issues regarding the meaning and use of concepts, procedures and interpretation. Content analysis illustrates the use of several concepts that relate to research procedures to achieve trustworthiness, credibility, dependability and transferability. ${ }^{[29,30]}$ A qualitative research design that relies on trustworthiness, transparency, verification, and reflexivity and that is "information driven" can be helpful when developing insightful and appropriate interpretations within nursing. ${ }^{[31]}$ An inductive methodological approach was used to analyze the data based on the content of nurses' thoughts and experiences regarding documentation of care plans. ${ }^{[29,30]}$

\subsection{Data collection}

A small convenience sample that is appropriate for qualitative methods was used. ${ }^{[31]}$ The inclusion criteria for participation were registered nurses (RN) over the age of 18 years with the ability to understand and speak Swedish and at least six-month experiences as a registered nurse in medical ward. Two of the authors (DH, HL) sent out an inquiry and an informational letter by email regarding the aim, confidentiality and voluntary participation to all employed $\mathrm{RN}(\mathrm{n}=20)$ at one internal medical ward in one university hospital consistent with the inclusion criteria. Two of the authors ( $\mathrm{DH}$, HL) contacted these nurses $(n=20)$ by text messages (mail, mobile phone) and informed them about the current study. Two reminders (text messages) were sent out, and the first six nurses who were interested in participation were included. The ethical guidelines for human and social research were considered throughout the study. ${ }^{[32]}$ The data were collected in October 2018, and the participants $(n=6)$ were informed about the aim and study procedures; confidentiality was assured before the interviews were carried out, which were all conducted in Swedish and started with background questions, including questions regarding age, education and personal experience with healthcare. Furthermore, the data collection focused on five perspectives, namely, care plan, documentation, medical record system, person-centred care and future aspects regarding care plans. The interviews started with "Tell me about your experience of care plans?" Based on the answers, related questions were asked regarding above five perspectives. Examples of situations such as positive and negative aspects of documentation of care plans were explored, and clarifications and further elaborations were made. The interviews lasted between 30 to 50 minutes and were performed individually by two of the authors (DH, HL); all interviews were recorded and then transcribed verbatim. The participants were RN (27-46 years) with experience as an $\mathrm{RN}$ (0.5-20 years).

\subsection{Data analysis}

The interviews were analyzed by using manifest qualitative content analysis ${ }^{[29,30]}$ to interpret the meaning from the data content to address trustworthiness, ${ }^{[31]}$ with examples drawn from the area of nurses' experience of working with care plans in at a medical ward. Written words were the basis for the analysis, which was performed in the following steps (15) which are described in Table 1 as examples of the analysis process: (1) The transcripts were read and reread to obtain an understanding of and familiarity with the text; (2) Meaning units (words, sentences or paragraphs) that corresponded to the content areas were selected by using an inductive approach concerning (a) uncertainty and (b) high workload; (3) Each meaning unit was condensed into a description of its content and labelled with one of 52 codes for example lack of IT-support and time consuming; (4) Categories were identified and grouped related to the codes; and (5) One category was identified (improving patient safety) and three subcategories were grouped (managing high workload, collaboration improves documentation, creating structure in the medical record) to respond to nurses experiences with care plans. The findings are illustrated with quotes.

\subsection{Ethical considerations}

Ethical approval and permission for the study were obtained from the manager of the medical department at Sahlgrenska University Hospital and from the first line managers in the medical ward (participants' workplace). No ethical approval was used due to Swedish rules and guidelines regarding student theses and/or projects regarding quality improvement that have no negative effects on participants. ${ }^{[18,32]}$ Respect for the individual nurse was a main concern during the study. 
All nurses were informed (verbally, in writing) and confirmed (two of the authors DH, HL) and the participants. Respect by a signed consent form. Moreover, no names were used, for the participants' integrity and autonomy was thereby and the results are described in categories without identifi- shown. ${ }^{[32]}$ cations. There was no relationship between the interviewers

Table 1. Examples of the analysis processes

\begin{tabular}{lllll}
\hline Meaning unit & Condensation & Code & Subcategory & Category \\
\hline $\begin{array}{l}\text { "That one gets insufficient in the } \\
\text { documentation, had we been more } \\
\text { staff then you had more time to write } \\
\begin{array}{l}\text { updating care plans like that too it will } \\
\text { not be as stressful." }\end{array}\end{array}$ & $\begin{array}{l}\text { More staff ... insufficient in } \\
\text { documentation ... more staff } \\
\text { gives more time to update } \\
\text { care plans }\end{array}$ & High workload & $\begin{array}{l}\text { Managing high } \\
\text { workload }\end{array}$ & $\begin{array}{l}\text { Improving } \\
\text { patient safety }\end{array}$ \\
$\begin{array}{l}\text { time one should complement each } \\
\text { other." }\end{array}$ & $\begin{array}{l}\text { Instead of opening each line } \\
\text {... complement each other }\end{array}$ & $\begin{array}{l}\text { Complementary } \\
\text { work }\end{array}$ & $\begin{array}{l}\text { Collaboration } \\
\text { improves } \\
\text { documentation }\end{array}$ & Improving \\
\hline
\end{tabular}

\section{RESUlts}

The interview analysis resulted in creation of the category "improving patient safety" and three subcategories (managing high workload, collaboration improves documentation and creating structure in the medical record) (see Figure 1). The resulting outcome describes opportunities and obstacles faced by nurses in their daily work regarding care plans.

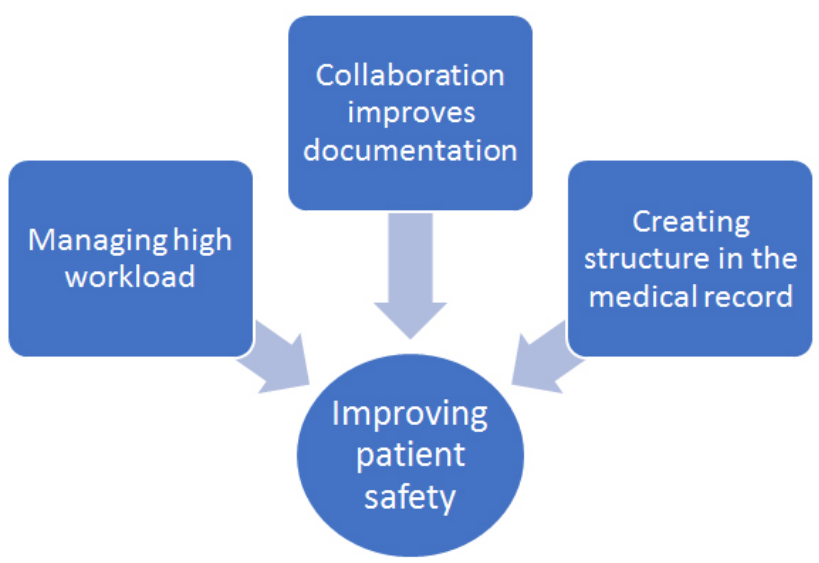

Figure 1. Overview of the categories

\subsection{Improving patient safety}

The improving patient safety category includes managing high workload, collaboration improves documentation and creating structure in the medical records.

Nurses report that nursing assessment results in care plans that create structure to achieve given goals. However, barriers, such as uncertainty regarding how documentation and risk assessments are carried out, negatively influence patient safety. Therefore, nurses stress the significance of improving the documentation structure within the medical records from an interprofessional perspective and prioritizing implementaPublished by Sciedu Press tion of care plans in their daily work. However, nurses' high workloads due to the shortage of nurses create a stressful working environment in relation to their responsibility for a high quality of care. Nurses highlight that limited participation in daily nursing activities causes moral stress. Extensive nursing documentation, including arrival talks and various contacts with health professionals regarding their patients' needs, resources and conditions (medical and nursing tasks), were described as time-consuming. Moreover, a lack of regular evaluation of existing care plans is stressed as a barrier to documentation that receives less attention and negatively influences patient safety. The limited number of care plans due to limitations with the nursing status, plans and reports affect patient safety, and thus coordination with different health professionals is needed to solve the relationships among patients' needs, resources and conditions (medical and nursing tasks).

According to nurses, documentation within medical records (IT system) is based on risk assessments, which sometimes are perceived as unnecessary and time-consuming, such as the fall-risk instrument regarding individual needs. Furthermore, nurses highlight that extended hospital stays call for extensive documentation in the medical records, with a risk for "lost" data when information is included in several places in duplicate or triplicate. The participants argue the significance of clear information stated in one place instead of repeated data entered in numerous statuses made by different health professionals and stress that the documentation is illogical and difficult to handle for all involved.

In summary, nursing documentation is described as a timeconsuming duty for nurses that causes moral stress. Moreover, repeated data entry by different health professionals within the medical record influences patient safety. There- 
fore, improvement, such as a structure that simplifies written documentation without repeated data, is highlighted to facilitate mutual care plans becoming a natural part of daily work.

\subsection{Managing high workload}

The managing high workload category is described as completing work during the work day in relation to the shortage of nurses, limited resources and extensive nursing needs (i.e., to provide best practice to all patients in the ward with support of care plans).

Nurses report deficiencies in nursing documentation due to limited resources, which contributes to the stressful working environment in which a variety of nursing tasks based on different needs arise during daily work. Furthermore, nurses report that documentation in the medical record is broken down by occupational categories in combination with a large amount of documentation (examinations and planning) in different places within the record, which contributes to a lack of overview of patient safety. Nurses highlight that the above lack of common interprofessional information leads to misconceptions and uncertainty in healthcare. The participants stress that a stressful work situation results in fewer care plans, although patient-close and direct care are prioritized in daily work.

"Those (other occupational categories) probably see the patient more than we do. Because we are very much with the computer, work a lot at the medicine wagon, we mix antibiotics... Specific team members, such as the physiotherapist, can go away with the patient for an hour and are just with them. Nurses do care for several patients; they get to know the patients on a deeper level. However, I'm not in direct care enough to be person-centered." (Nurse 6)

Nurses are positive that PCC plans are an efficient means of giving patients and relatives written information concerning treatment and planned admission at an early stage during the hospital stay. They believe that PCC improves nursing by ensuring less interruption of their daily work due to the staff-patient partnership and involvement in care planning during the hospital stay. Receiving written information in connection with admission to the ward will increase collaboration with all individuals involved (staff, patient, and relatives). Furthermore, nurses are skeptical of documenting the preliminary admission day as a goal in the care plan. Instead, they note that the goal for each hospital stay should be provided as accurately and as soon as possible for all patients. In summary, nursing documentation is described as a time-consuming task within a stressful working environment.

\subsection{Collaboration improves documentation}

The collaboration improves documentation category is described as a common endeavor among staff, patients and relatives for best practice with mutual responsibility. Nurses describe problems due to risk assessments and teamwork, such as invasive routines and patterns that affect visibility within the medical records. They stress that documenting care plans is difficult and that teamwork is significant for supporting, sharing and participating in the documentation work. However, teamwork is stressed as limited when assistant nurses are not allowed to document nursing tasks in the medical record. Moreover, different formulations (language) of body text/data within the medical records contribute to uncertainty that is grounded in professional education (registered nurse versus physician).

According to nurses, collaboration works well for patients suffering from a stroke, and they argue that the same structured interprofessional discussions (team rounds) can be used for general internal medicine patients on the ward. They stress that routines such as team rounds contribute to a common picture of a patient's situation when different crossprofessional perspectives are aired. This joint review results in the development of common goals for each patient and is the reason a mutual care plan is created. However, team rounds are expressed as time-consuming and a barrier when they need to be performed for all patients at the ward due to the high workload among staff. Therefore, participants highlight room for improvement in routines; they stress that a role model is needed to remove unnecessary and timeconsuming work and to develop uniform teamwork around care plans for all patients regardless of their diagnoses. One nurse described this issue as follows:

"We should jointly strive so that all patients receive the best possible care and that is something every team member should work for, I think." (Nurse 1)

Furthermore, different health professionals use different routines for documentation in the patient's care plan, leading to uncertainty. Therefore, nurses stress a need for increased collaboration among team members to improve the quality of care. They highlight common and structured documentation that includes a patient's resources based on PCC with a mutual care plan during the hospital stay.

"Instead of opening each line all the time, we should complement each other... more common plans, in which all occupational categories write to obtain better cohesion for a patient in the center." (Nurse 5)

One part of the documentation that nurses consider wellfunctioning is the "risk of malnutrition". In this plan, dif- 
ferent health professionals, such as the dietician and speech therapist, can document together with nurses within the same plan, which is perceived as well-functioning teamwork. However, nurses describe frustration that dieticians are not allowed to document in the "plan for nutrition", which creates uncertainty about how the electronic documentation system works, since there are variations in which health professionals can document at given locations within the medical record. They argue that care plans are used to a limited extent among team members due to an inefficient IT system.

"In the best of worlds, all categories would pull their workload; for example, occupational therapists and physiotherapists write their part, and nurses write their part, but we as nurses pull a heavy workload to write and document and inform all health professionals... Our time is limited, and documentation is less prioritized during daily work due to lack of time." (Nurse 1)

In summary, collaboration towards partnership is regarded as significant for patient safety.

\subsection{Creating structure in the medical record}

The creating structure category in the medical record is described as the conditions for implementing a person-centered approach by maintaining and developing routines regarding by whom, on what topic and where documentation take places in the medical record. Nurses highlight that a limited number of care plans are documented due to the lack of needed information; in other words, few care plans are developed and used in an interprofessional manner. Moreover, they emphasize the importance of care plans being established and documented at the earliest possible stage to focus on health problems without nursing notes/statuses. A systematic structure is highlighted by the nurses as facilitators to find and take part in relevant information for the best treatment outcome based on tests and investigations. In addition, because an up-to-date care plans is significant, continual revision represents significant work for all health professionals regarding what the patient has been through during their hospital stay. This issue is described as follows:

"It is important that everyone opens, follows them and writes in the same care plan. It may take a while before you discover things by yourself... for example, a patient gets shortness of breath in the back position. I may panic and think that, 'oh he can't breathe!' But if I had read the care plan and viewed that this happens every night, then I would know... so you have to read so you know if this happens, then we do this." (Nurse 6)

The most common care plans in the ward are those based on risk assessments made by nurses. They stress that these care

Published by Sciedu Press plans are easy to establish and follow, because they clearly point out a patient's physical problems, such as plans for nutrition, elimination, wounds, etc. Moreover, care plans based on risk assessments have less time-consuming documentation procedures and thus are used more frequently by nurses. Plans concerning a patient's mental health problems, such as anxiety, are described as rare, although these tasks are difficult for nurses to formulate. Furthermore, nurses highlight that their experience and knowledge influence whether and how care plans are developed. The participants argue that newly educated nurses are uncertain about how and when care plans should be established. Therefore, they stress improvement in nursing education and introduction in the workplace to a nurse's duty and responsibility regarding care plan documentation. Nurses also argue that a high workload results in limited opportunities to support newly employed nurses within documentation procedures and is a reason why a limited number of care plans is produced.

“... you have to be able to do nursing in order to develop or offer a care plan. It is only now that I can offer a slightly better care plan because of the experience I have acquired in the area; now I start to think and ask the patient what she/he wants or inform them about opportunities and so on." (Nurse 2)

According to nurses, the patient's voice is more or less invisible in the medical record, because current documentation is based on the health professional's perspective. They explain that nursing diagnoses and care plans are mainly used by healthcare professionals to develop and evaluate the effects of healthcare. Therefore, participants highlight that PCC plans can be a tool to provide conditions for involvement and partnership with patients and staff and ensure a high quality of care (i.e., patient safety). Nurses emphasize the significance of having a natural dialogue with patients and their relatives regarding daily care and requiring staff (the team) to facilitate shared information towards the care plan. However, they express concerns that introduction of PCC plans will be time-consuming before new routines are developed and secured, which will require rethinking among health professionals regarding future collaboration.

“... time is a barrier; we have to be effective so we don't talk to patients about how they feel and what their problems are; then we will just lose a lot of time that doesn't benefit us or the patient." (Nurse 4)

Patient involvement minimizes misconceptions about nursing; however, nurses highlight problems that may arise due to differences between patients and health professionals regarding needs and treatments. They believe that some patients want to be included in their healthcare, whereas others may 
not be interested at all and/or may lack the ability to be actively involved. Furthermore, nurses describe language use as a barrier for partnership in care plans, because written text needs to be objective and uniform as well as understandable for all involved parties. Therefore, nurses request technical aids (templates and IT support) and technology to facilitate documentation on a daily basis in a smooth and efficient manner. In summary, teamwork is described as significant for the ability to share and participate in the same care plan.

\section{Discussion}

The aim of the present study was to describe nurses' experiences working with care plans at an internal medical ward at a university hospital in Sweden, which might be considered to have been achieved. The main results focus on opportunities and obstacles for patient safety based on care plan documentation within the medical record. Systematic use of care plans requires interprofessional collaboration, which is a challenge within a stressful work environment. Improvement in routines to achieve a common interprofessional structure due to documentation is highlighted, as is involvement from the patient's perspective (i.e., a mutual care plan for all involved instead of simply a work tool for the health professionals). Therefore, a shift from traditional patient-centered care (health professionals' perspectives and informing the patient) to PCC (expert patient to expert health professionals and mutual respect) is needed. ${ }^{[1,2,11]}$ Research shows that competence (ability) requires experience and learning from different angles. ${ }^{[33]}$ Moreover, PCC is grounded from an ethical perspective ${ }^{[10]}$ that is in line with the code of ethics for nurses, ${ }^{[6]} \mathrm{PCC}$ is one way to promote health, prevent illness and alleviate suffering that is in line with people's rights and self-determination (i.e., to adapt to patient's needs, resources and conditions). ${ }^{[1,2,4]}$

The results of the present study show that care plans need conditions for patient involvement by using simple everyday language and a systematic visible structure in medical records that harmonizes with earlier research; ${ }^{[16,19,34]}$ these studies point out that IT support and teamwork are crucial aspects. Moreover, support of an ethical approach that forms the basis of $\mathrm{PCC}^{[1,2,11]}$ can guide and improve teamwork for all involved parties (staff, patient, and relatives) using all available resources, including patients. ${ }^{[35]}$

PCC has been implemented in Sweden ${ }^{[5]}$ and other countries ${ }^{[36,37]}$ as a drive to support nurses worldwide, who are inspired by others to achieve effective, high quality care. In the present study, nurses describe a strong desire to involve the patient and relatives to a greater extent and to improve healthcare by visualizing the patient's voice in the care plan. ${ }^{[23,38]}$ These goals may significantly affect the ability of nurses to adapt to a patient's needs, resources and conditions, ${ }^{[1,2,4]}$ as advocated in partnerships with the GPCC. ${ }^{[11]}$ According to Broderick and Coffey, ${ }^{[38]}$ documentation that focuses on the unique person contributes to a meaningful relationship, which is a so-called partnership between health professionals and patients. Partnership with patients creates conditions to participate in healthcare that are documented in a mutual care plan. Co creation (patient and nurse) of goals allows the hospital to stay grounded concerning the patient's needs, resources and conditions but is limited because the goals are based on routines from the health professional's perspective. This conclusion is also in line with the $\mathrm{ICN}^{[6]}$ and the Swedish Patient Act. ${ }^{[9]}$ However, there are limitations regarding visualization of the patient's voice in care plans that have to be improved by implementing PCC. ${ }^{[23]}$

For documentation of a PCC plan, a relationship as equal partners between the nurse and patient is significant (i.e., respectful communication and commitment facilitate collaboration). Therefore, organizations and individuals who introduce PCC need to be aware of social and political forces that basically shape and limit daily work. For example, Sharp, McAllister and Broadbent ${ }^{[39]}$ stress that nursing actions are prioritized by the urgency of every task. Factors that limit a nurse's ability to perform more person-centered work are the need to perform too many demanding tasks; thus, complicated and time-consuming documentation systems (IT) need to be improved. According to the pressure of healthcare services, high demands are placed on nurses in response to the patient's needs, resources and conditions (physical, psychological, social and spiritual). Morale stress is influenced by organizational systems and limited resources, ${ }^{[40]}$ but job satisfaction lowers the sense of work-related frustration. ${ }^{[41]}$ At the same time, nurses have to fulfil time-consuming routine work, such as risk assessments, using quality registers with limited use due to a patient's needs. This increased administrative work within a high workload contributes to nurses' experiences of morale stress working with care plans, and teamwork is one tool to improve the working environment. $^{[42]}$

Research ${ }^{[43]}$ highlights the importance of a working environment in harmony with nurses' ethical values to decrease morale stress, absence and staff turnover. Nurses' ethical stress is diminished when they understand the cause of action and decisions made in the workplace. Moreover, the nurses' professional qualifications directive ${ }^{[44]}$ can help support their obligation for care plan documentation in the medical record. Current knowledge can be used to discuss healthcare and treatment with team members, patients and relatives. One approach is to create available meeting rooms near the workplace and to invite and encourage interprofessional meetings; 
another approach is to change routines for medical rounds and reporting systems to visualize partnerships by focusing on the patient's perspective. One successful example is bedside reports, ${ }^{[17]}$ which share information management (staff and patient) based on facts that are structured using SBAR (situation, background, current state of play, recommendations) to decrease unnecessary information (sensitive aspects) built upon personal values. The above routines can increase morale stress by using all resources as efficiently as possible in the ward through increased teamwork due to mutual care plans.

McCormack et al. ${ }^{[3]}$ report that nurses struggle to apply PCC and provide a high quality of care in a manner that ensures patient safety. Similar results found in the present study can be termed morale stress, because nurses strive for a high quality of healthcare. ${ }^{[40-42]}$ The results show that nurses experiences with care plans vary; some nurses experienced formulating care plans more easily than others due to their specific interests and knowledge of documentation and IT. Newly graduated nurses have limited knowledge from nursing education regarding how to formulate and document care plans in medical records. ${ }^{[45]}$ This lack is an obstacle, since care plans are aimed at allowing all patients to achieve high quality care and to ensure patient safety. Furthermore, the need for experienced nurses to teach newly educated nurses about documentation is time consuming, and thus the curriculum within nursing education regarding documentation procedures needs to be improved. ${ }^{[23,45]}$ One suggestion is to include both teaching and examination-based elements focused on documentation of care plans supported by computerized clinical nursing practice support systems. ${ }^{[34]}$ This goal is expressed in terms of skill and the ability to plan orally and in written report form and to discuss measures and treatment results with interested parties in accordance with relevant regulations, routines, best practice and so on. However, nurses' experiences with obstacles during work make it difficult for them to plan, document and update care plans in a manner that ensures patient safety. According to Swedish law, ${ }^{[46]}$ nursing measures documented in the medical records must be examined and evaluated. However, the IT documentation system described by the participants includes many limitations. Therefore, nurses advocate improvement, such as a supportive IT system that simplifies and facilitates nurse's time-consuming documentation duty due to increasing administrative work. Participants request technical aids, such as mobile devices, including clipboards (iPad), and a synchronized IT system to reduce double documentation with simple documentation functions, such as a "click in a box" function instead of body text. However, research ${ }^{\text {[34] }}$ shows limitations due to evidence-based IT decision support.
Support for the key steps of patient assessment, problem identification, care plan and outcome evaluation by the IT system will effectively help nurses with clinical decision making in partnership with the team, including the patient.

The results show that the shortage of nurses together with unstructured routines for documentation and a limited IT system within the medical record negatively influence the number of established care plans. Furthermore, nurses report uncertainty in how to implement PCC plans when they have problems performing traditional care plans for all patients. One suggestion is to make available resources visible and to ensure expert to expert partnership in line with the study of Butterworth. ${ }^{[23]}$ PCC plans can replace standardized care plan documentation, which are described as unclear and include double documentation. Therefore, the conclusion is that PCC plans avoid time-consuming duplication of work; instead of documenting similar information in several places in the medical record, documentation in a mutual care plan occurs once at the same place. Due to staff member limitations, healthcare organizations have no room for double documentation and misunderstandings between health professionals about patient safety. Therefore, documentation needs to be "unlocked" for all health professionals, which is in contrast to the current system in which physiotherapists' documentation is locked for nurses and vice versa.

Working with mutual care plans ${ }^{[5]}$ is an important part of nursing that improves the high quality of care. The results show that the care plan quality is influenced by how the documentation procedures are performed and thereafter how the plan is followed and revised on a regular basis. Barriers, such as a limited timetable and collaboration as well as lack of a documentation structure within the medical records, have been described by others. ${ }^{[15]}$ Moreover, visible partnership from the patient's perspective is reinforced by Swedish legislation ${ }^{[9,18]}$ and research; $;^{[1,2,38]}$ therefore, PCC plans are tools to improve cooperation of healthcare, such as the choice of treatment. ${ }^{[23]}$ However, healthcare is still based on illness (biomedical perspective) and not the unique person, which confirms a need for changed routines to implement PCC for tomorrow's healthcare. ${ }^{[5,36]}$

Moreover, the increased number of fragile elderly people with complex care needs affects healthcare for health professionals with a high workload, such as nurses, which contributes to the need for improvement in PCC implementation to ensure efficient quality of care. Based on nurses' concerns about their work structure (content and tasks) in relation to collaboration with involved health professionals, implementation of a PCC plan needs to occur in a structural manner. By using evidence-based knowledge, teamwork is improved 
even within a hierarchical organization. ${ }^{[35]}$ Nurses agree on the need for a well-informed patient and/or family member, because admission to the hospital reduces uncertainties regarding the healthcare content and structure, which facilitates patient safety within the work environment. Inclusion of a mutual care plan in the medical records facilitates the relationship (patient-nurse) as a partnership (expert-expert) i.e., in practice, patients are partners with resources. ${ }^{[6]}$

Healthcare is planned and documented, but increased responsibility among all health professionals for care plans needs to be highlighted to create an efficient work distribution. A mutual PCC plan strengthens the team when misconceptions are managed, which in turn increases patient safety. According to Rosengren, ${ }^{[47]}$ different people have different skills in a team, and thus documentation by individual health professionals in the same plan increases knowledge of the best approach for each patient.

Successful implementation of PCC plans requires a clear and simple structure for interprofessional documentation (collaboration improves patient safety) ${ }^{[11]}$ However, Abrahamson et al. ${ }^{[22]}$ stress that PCC implementation requires change in organization work processes to develop mutual goals and thus that communication is crucial. Additionally, Khuan and Juni ${ }^{[48]}$ emphasize the need for changes due to patient involvement in connection with PCC implementation. Therefore, collaboration among hospitals (caregivers), universities (educators) and health professionals is a prerequisite for PCC implementation with a focus on partnership among those involved.

\section{Limitations}

This study was carried out in one ward at one hospital, which limits the ability to generalize the results to other specialties/departments/hospitals. Another limitation is the limited number of participants $(n=6)$; therefore, further investigation of work with care plans at different specialties/wards in international hospitals is needed. However, this study used a well-established systematic scientific method (content analysis), ${ }^{[29,30]}$ which contributed to the trustworthiness of the study results and was consistent with earlier research. According to the above limitations, further studies are needed to develop and broaden knowledge of care plan documentation and to improve patient safety within hospital settings.

\section{Conclusions}

A nurse's daily work includes care plan documentation within medical records. However, the quality of the care plan is influenced by how the documentation is implemented and followed, including the language used, structure of the body text and regular revisions. To implement PCC plans, further work is needed to develop the structure and content of mutual plans. Hence, there is also need for improved organizational collaboration to develop routines for joint interprofessional documentation due to limited resources and to ensure that the patient's voice is heard. Thus, clarifying the overall picture of the patient's health status is not sufficient. PCC plans challenge the documentation procedure to avoid repetition and/or misunderstanding in the mutual plan. PCC requires three parts; partnership (mutual respect for all involved), narrative/story (listening to the patient combined with tests) and documentation (care plan). Therefore, implementing PCC plans requires work at several levels of the hospital (department and management) instead of only in a specific ward. However, improvement starts as interprofessional engagement, willingness and interest to work in a person-centered manner that is grounded in knowledge of documentation. Therefore, PCC is a tool that can facilitate and simplify nurses' daily work.

\section{ACKNOWLEDGEMENTS}

We thank the managers, who organized the data collection, and nurses who participated in the study at Sahlgrenska University Hospital, Gothenburg, Sweden and the University of Gothenburg Centre for Person-Centred Care (GPCC), Gothenburg, Sweden.

\section{Conflicts of Interest Disclosure}

No conflict of interest has been declared by the authors.

\section{REFERENCES}

[1] Ekman I, Swedberg K, Taft C, et al. Person-centered care-Ready for prime time. European Journal of Cardiovascular Nursing. 2011; 10(4): 248-251. PMid: 21764386. https ://doi.org/10.1016/j. ejcnurse.2011.06.008

[2] Ekman I, Hedman H, Swedberg K, et al. Commentary: Swedish initiative on person-centred care. BMJ. 2015; 350: h160. PMid: 25670185 https://doi.org/10.1136/bmj.h160

[3] McCormack B, Karlsson B, Dewing J, et al. Exploring personcentredness: a qualitative meta-synthesis of four studies. Scandinavian Journal of Caring Sciences. 2010; 24: 620-634. PMid: 21050249. https://doi.org/10.1111/j.1471-6712.2010.00814.x

[4] McCormack B, Dewing J, McCance T. Developing person-centred care: Addressing contextual challenges through practice development. Online Journal of Issues in Nursing. 2011; 16(2): 1. https: //doi.org/10.3912/ojin 
[5] Vårdanalys. Från mottagare till medskapare. Ett kunskapsunderlag för mer personcentrerad hälso- och sjukvård (From recipients to cocreators. A knowledge base for more person-centred care). Rapport 2018: 8. Stockholm: Vårdanalys; 2018. (In Swedish)

[6] International Council of Nurses, ICN. The ICN code of ethics for nurses. 2012. Accessed on 6th May 2019. Available from: https://ww. .icn.ch/sites/default/files/inlin e-files/2012_ICN_Codeofethicsfornurses_\%20eng.pdf

[7] Jansson I, Forsberg A. How do nurses and ward managers perceive that evidence-based sources are obtained to inform relevant nursing interventions? - an exploratory study. Journal of Clinical Nursing. 2016; 25(5-6): 769-76. PMid: 26814374. https: //doi.org/10.1111/jocn. 13095

[8] Ehnfors M, Ehrenberg A, Thorell-Ekstrand I, et al. Om en forskningsbaserad modell för dokumentation av omvårdnad i patientjournalen. (VIPS text book. About a research-based model for documentation of nursing care in the medical record) Lund: Studentlitteratur; 2000. (In Swedish)

[9] Swedish Code of Statutes. Patientlag (Patient act). Stockholm: Socialdepartementet; 2014. 821 p. Available from: https://www. riksdagen.se/sv/dokument-lagar/dokument/svenskforf attningssamling/patientlag-2014821_sfs-2014-821. (In Swedish)

[10] Ricoeur P. Oneself as another. Chicago: The University of Chicago Press; 1992.

[11] GPCC - Centre for Person-centred care. Person-centred care. 6th May 2019. Available from: https ://gpcc.gu.se/

[12] Björvell C, Wredling R, Thorell-Ekstrand I. Improving Documentation Using a Nursing Model. Journal of Advanced Nursing. 2003a; 43: 402-410. PMid: 12887359. https://doi.org/10.1046/j. 1365-2648.2003.02751.x

[13] Björvell C, Wredling R, Thorell-Ekstrand I. Prerequisites and consequences of nursing documentation in patient records as perceived by a group of Registered Nurses. Journal of Clinical Nursing. 2003b; 12 : 206-204. PMid: 12603552. https://doi.org/10.1046/j.1365 $-2702.2003 .00723 . \mathrm{x}$

[14] Heather Herdman T. Omvårdnadsdiagnoser - definitioner och klassifikation 2012-2014. (Nursing diagnoses - definitions and classification 2012-2014). Lund: Studentlitteratur; 2013. (In Swedish)

[15] Thoroddsen A, Ehrenberg A, Sermeus W, et al. A survey of nursing documentation and standards in European countries. Nursing Informatics Journal. 2012; 406: eCollection 2012. PMid: 24199130.

[16] Penoyer D, Cortelyou-Ward K, Noblin A, et al. Use of electronic health record documentation by healthcare workers in an acute care hospital system. Journal of Healthcare Management. 2014; 59(2): 130-144. PMid: 24783371. https ://doi.org/10.1097/001155 14-201403000-00008

[17] Baker S. Bedside shift report improves patient safety and nurse accountability. Journal of Emergency Nursing. 2010; 36(4): 355-358. PMid: 20624574. https://doi .org/10.1016/j.jen.2010.03. 009

[18] Swedish Code of Statutes. Hälso- och sjukvårdslagen (Health and Medical Service Act). Stockholm: Socialdepartementet; 2017. 30 p. Available from: https://www.riksdagen.se/sv/dokument-1 agar/dokument/svenskforfattningssamling/halso--och -sjukvardslag-1982763_sfs-1982-763. (In Swedish)

[19] Collins S, Gazarian P, Stade D, et al. Clinical Workflow Observations to Identify Opportunities for Nurse, Physicians and Patients to Share a Patient-centered Plan of Care. AMIA Annual Symposium Proceedings. 2014; 14; 414-423. PMid: 25954345.

[20] Liu BS, Johnston JM. Systematic Review of Qualitative Study in Multidisciplinary Teamwork in Healthcare. International Journal of
Epidemiology. 2015; 44(1): i235-i236. https : //doi .org/10.109 3/ije/dyv096.419

[21] Rosen M, DiazGranados D, Dietz A, et al. Teamwork in Healthcare: Key Discoveries Enabling Safer, High-quality care. American Psychologist. 2018; 73(4): 433-450. PMid: 29792459. https : //doi.org/10.1037/amp0000298

[22] Abrahamson K, Myers J, Nazir A. Implementation of a PersonCentered Medical Care Model in a Skilled Nursing Facility: A Pilot Evaluation. 2017; 18(6): 539-543. PMid: 28431908. https: //doi.org/10.1016/j.jamda.2017.03.001

[23] Butterworth C. How to achieve a person-centred writing style in care plans. Nursing Older People. 2012; 24(8): 21-26. PMid: 23189502. https://doi.org/10.7748/nop2012.10.24.8.21.c9310

[24] Kitwood T, Bredin K. Towards a theory of Dementia care: Personhood and well-being. Ageing and Society. 1992; 12: 269-287. PMid: 11654434. https://doi.org/10.1017/S0144686X0000502X

[25] Chevakasemsook A, Chapman Y, Francis K, et al. The study of nursing documentation complexities. International Journal of Nursing Practice. 2006; 12: 366-374. PMid: 17176310. https://doi.org/ $10.1111 / j .1440-172 \mathrm{X} .2006 .00596 . \mathrm{x}$

[26] Wolf A, Moore L, Lydahl D, et al. The realities of partnership in person-centred care: A qualitative interview study with patients and professionals. BMJ Open. 2017; 7(7): e016491. PMid: 28716793 https://doi.org/10.1136/bmjopen-2017-016491

[27] Horrell J, Lloyd H, Sugavanam T, et al. Creating and facilitating change for Person-Centred Coordinated Care (P3C): The development of the Organisational Change Tool (P3C-OCT). Health Expectations. 2018; 21(2): 448-456. PMid: 29139220. https : //doi.org/10.1111/hex.12631

[28] Sahlgrenska University Hospital. Om sjukhuset (About the hospital) Accessed on 6th May 2019. Available from: https://www2.sahlg renska.se/sv\%2FSU\%2FOm-s jukhuset\%2F. (In Swedish)

[29] Graneheim UH, Lundman B. Qualitative content analysis in nursing research: concepts, procedures and measures to achieve trustworthiness. Nurse Education Today. 2004; 24: 105-112. PMid: 14769454 https://doi.org/10.1016/j.nedt.2003.10.001

[30] Graneheim UH, Lindgren BM, Lundman B. Methodological challenges in qualitative content analysis: A discussion paper. Nurse Education Today. 2017; 56: 29-34. PMid: 28651100. https : //doi.org/10.1016/j.nedt.2017.06.002

[31] Polit D, Beck CT. Nursing research: Generating and assessing evidence for nursing practice. Wolters Kluwer Health/Lippincott Williams and Wilkins, Philadelphia. 2017.

[32] Codex. Rules \& guidelines for research. The humanities and social sciences. Accessed on 6th May 2019. Available from: http: //codex.vr.se/en/forskninghumsam.shtml

[33] Fukada M. Nursing Competency: Definition, Structure and Development. Yonago Acta Medica. 2018; 61(1): 1-7. PMid: 29599616. https://doi.org/10.33160/yam.2018.03.001

[34] Lee S. Features of computerized clinical decision support systems supportive of nursing practice: A literature review. Computers Informatics Nursing. 2013; 31(10): 477-495. PMid: 23958964 https://doi.org/10.1097/01.NCN.0000432127.99644.25

[35] Rosengren K. Person-centred care: A qualitative study on first line managers' experiences on its implementation. Health Services Management Research. 2016; 29(3): 42-49. https ://doi.org/10.1 $177 / 0951484816637748$

[36] International Alliance of Patients' Organizations, IAPO. The global voice for patient-centred healthcare. Accessed on 6th May 2019 Available from: https ://www.iapo.org.uk 
[37] World Health Organization, WHO. Patient safety. Accessed on 6th May 2019. Available from: https://www . who.int/patientsaf ety/patients_for_patient/en/

[38] Broderick MC, Coffey A. Person-centred care in nursing documentation. International Journal of Older People Nursing. 2013; 28(4): 30918. PMid: 23216647. https://doi.org/10.1111/opn. 12012

[39] Sharp S, Mcallister M, Broadbent M. The tension between person centred and task focused care in an acute surgical setting: A critical ethnography. Collegian. 2017; 25(1): 11-17. https://doi .org/10 $.1016 / j$. colegn. 2017.02.002

[40] Abraham L, Thom O, Greenslade J, et al. Morale stress and coping strategies of staff working in the emergency department: A comparison of two different sized departments. Emergency Medicine Australasia. 2018; 30(3): 375-381. PMid: 29363265. https : //doi . org/10.1111/1742-6723.12895

[41] Wang PH, Ku YC, Chen CC, et al. Work-related frustration among senior nurses at a medical center. Journal of Clinical Nursing. 2016; 25(13-14): 2040-2051. PMid: 27140170. https://doi.org/10.1 $111 /$ jocn. 13241

[42] Horn D, Lindström M, Rosengren K. Managing a Stressful Work Environment through Improved Teamwork - A Qualitative Content Analysis of Nurses Working Environment within Emergency Care. International Archives of Nursing and Health Care. 2018; 4: 109. https://doi.org/10.23937/2469-5823/15100109
[43] Gaudine A, Thorne L. Nurses' ethical conflict with hospitals: a longitudinal study of outcomes. Nursing Ethics. 2012; 19(6): 727737. PMid: 22619238. https ://doi .org/10.1177/0969733011 421626

[44] European Federation of Nurses Associations, EFN. EFN Guideline for the Implementation of Article 31 of the Mutual Recognition of Professional Qualifications Directive 2005/36/EC, Directive 2013/55EU. Accessed on 6th May 2019. Available from: http://www. efnweb.be/?page_id=6897

[45] Ingvarsson E, Verho J, Rosengren K. Managing Uncertainty in Nursing - Newly Graduated Nurses' Experiences of Introduction to Nursing Profession. International Archives of Nursing and Health Care. 2019; 5: 119. https://doi.org/10.23937/2469-5823/1510 119

[46] Swedish Code of Statutes 2008:355. Patientdatalag (Act regarding Patient data). Stockholm: Socialdepartementet. Accessed on 6th May 2019. Available from: http://www.riksdagen.se/sv/Do kument-Lagar/Lagar/Svenskforfattningssamling/Patie ntdatalag2008355_sfs-2008-355/. (In Swedish)

[47] Rosengren K. Vårdledarskap- att utveckla och förbättra framtidens vård och omsorg. (Leadership for healthcare - to develop and improve care of the future). Lund: Studentlitteratur; 2014. (In Swedish)

[48] Khuan L, Juni MH. Nurses' Opinions of Patient Involvement in Relation to Patient-centered Care During Bedside Handovers. Asian Nursing Research. 2017; 11(3): 216-222. PMid: 28991603. https : //doi.org/10.1016/j.anr.2017.08.001 